\title{
Transition readiness among adolescents with rare endocrine conditions
}

\author{
Lisette van Alewijk', Kirsten Davidse', Karlijn Pellikaan', Judith van Eck², Anita C S Hokken-Koelega 2,3,4, \\ Theo C J Sas ${ }^{2,5}$, Sabine Hannema ${ }^{2,6}$, Aart J van der Lely ${ }^{1}$ and Laura C G de Graaff ${ }^{1,3}$ \\ ${ }^{1}$ Internal Medicine, Division of Endocrinology, Erasmus MC, University Medical Centre Rotterdam, Rotterdam, the Netherlands \\ 2Department of Paediatrics, Subdivision of Endocrinology, Erasmus University Medical Centre, Rotterdam, the Netherlands \\ ${ }^{3}$ Academic Centre for Growth, Erasmus University Medical Centre, Rotterdam, the Netherlands \\ ${ }^{4}$ Dutch Growth Research Foundation, Rotterdam, the Netherlands \\ ${ }^{5}$ Diabeter, National Diabetes Care and Research Centre, Rotterdam, the Netherlands \\ ${ }^{6}$ Department of Paediatric Endocrinology, Leiden University Medical Centre, Leiden, the Netherlands \\ Correspondence should be addressed to L C G de Graaff: I.degraaff@erasmusmc.nI
}

\begin{abstract}
Objective: Adolescents and young adults (AYA) with common endocrine disorders show a high dropout (up to 50\%) after the transfer from paediatric to adult endocrinology. Little is known about transition readiness in rare endocrine conditions ( $r E C$ ). This study aims to assess medical self-management skills (SMS) among AYA with rEC in relation to age and gender, in order to understand dropout and increase transition readiness.

Design: Cross-sectional study using web-based medical self-management questionnaires. Methods: Questionnaires consisting of 54 questions in seven domains were filled out by the adolescents before the first shared appointment with both paediatric and adult endocrinologist.

Results: Fifty-seven patients (median age 17 years, 25/57 females) participated and generally scored well on most items. However, one out of seven did not know the name of their disorder, one sixth of the glucocorticoid users did not know that dose should be adapted in case of illness or surgery, over one-fifth had never ordered their repeat prescriptions themselves and two-thirds had never had a conversation alone with their doctor.

Conclusions: Several SMS among patients with rEC are insufficient, with regard to medical knowledge, practical skills and communication. As SMS are only weakly related to nonmodifiable factors, such as age and gender, we recommend focussing on other factors to increase transition readiness. The timing, amount and 'mode' of medical information should be individualised. Transition checklists should be used to detect shortcomings in practical skills and communication, which can subsequently be trained with the help of parents, caregivers and/or e-technology.
\end{abstract}
Key Words
- transition readiness
- adolescent
- young adult
- self-management
- rare diseases
- endocrine

\section{Introduction}

Up to $50 \%$ of young adults with an endocrine disorder is lost to follow up after transfer to adult health care services (1). There is no consensus about the optimal timing of transition (2). Adolescents and young adults (AYA) have indicated that they are transition-ready between 17 and
40 years old, with the majority preferring the age of $18-24$ years for transfer $(3,4)$. This suggests that some AYA might not be fully prepared to take this step, which can lead to disengagement from healthcare. This disengagement from healthcare, or 'dropout', can lead to poor adherence https://ec.bioscientifica.com

https://doi.org/10.1530/EC-20-0304

(c) 2021 The authors Published by Bioscientifica Ltd

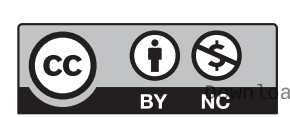

This work is licensed under a Creative Commons Attribution-NonCommercial 4.0 International License. ded from Bioscientifica.com at 04/26/2023 01:22:47PM 
to medication and even hospitalisation $(5,6)$. Therefore, paediatricians recommend starting the transition process much earlier, beginning at the age of 12 (7).

Apart from age, assessment of self-management skills (SMS) is a good indicator of transition readiness (8). Medical self-management is defined as 'maintaining satisfaction in living with a chronic disorder through managing the symptoms, medical care, and physical, physiological and social effects associated with the disorder' (9). Selfmanagement includes know-how of the disease and medication, adherence to medication and a healthy lifestyle, problem solving and symptom management (9, 10). Understanding which factors increase SMS (and thus transition readiness) might help prevent part of dropout.

Up to now, SMS and transition readiness have been mainly studied among AYA with non-endocrine diseases such as inflammatory bowel disease, sickle cell disease, kidney diseases or common endocrine disorders such as diabetes mellitus $(5,11,12,13,14,15,16,17,18,19$, 20, 21). For example, Monaghan et al. (22) provide an overview of best practices for health care professionals working with adolescents with diabetes type I who are ready for transition. 'Stimulating patient's autonomy' and 'schedule joint visits with paediatric and adult endocrinologists' are two examples of best practices recommended by Monaghan et al.

Information about transition readiness in rare endocrine conditions ( $\mathrm{rEC}$ ) is scarce. To minimise dropout after transfer to adult endocrine healthcare, it is essential to examine this particular group of patients in detail. Thus, we aimed to assess medical SMS among AYA with rEC and relate them to patient characteristics, in order to understand and improve transition readiness. To achieve this, we analysed the answers to a web-based survey that patients filled out before visiting the Rotterdam Young Adults Clinic (YAC), a multidisciplinary transition clinic for (young) adults with rare endocrine disorders.

\section{Methods}

This observational study was approved by the local ethical review board of the Erasmus University Medical Centre. Consent was obtained from all participants.

\section{Patient selection}

The survey was conducted in the Erasmus University Medical Centre, the Netherlands, prior to the first shared appointment with both paediatric and adult endocrinologist at the YAC. Before the implementation of the YAC, no structured transition program was available for patients with rEC. Since 2017, adolescents and young adults with $\mathrm{rEC}$ visit the YAC before their first appointment at the adult outpatient clinic. Filling out the SMS questionnaire before the first visit to the YAC is part of regular patient care. Patients do not receive any other questionnaires or written transition support prior to this first visit. For this study, we retrospectively analysed all questionnaires filled out between May 2017 and October 2019. We included questionnaires of patients who were diagnosed with rEC and were able to fill out the questionnaire online without the help of parents or caregivers. A minimum age of 15 years was required to participate. No maximum age was defined, as only patients of paediatric endocrinologists could participate. Patients diagnosed with diabetes mellitus were not included as the Diabetes Care and Research Centre 'Diabeter' takes care of these patients outside the hospital setting.

\section{Questionnaire}

The questionnaire used in this study was based on the questionnaires used in the so-called 'Ready Steady Go' transition program (see 'Acknowledgements' for details), which was developed for children and adolescents in the transition phase. In our study, the original questionnaire was adapted for this particular patient group. The original version of the questionnaire is provided as supplementary data (Supplementary The Ready Steady Go transition programme - Go, see section on supplementary materials given at the end of this article). The (web-based) questionnaire consisted of 54 questions classified into 7 domains that encompass a broad spectrum of medical and psychosocial components: (1) medical knowledge, (2) medication (other than glucocorticoids), (3) use of glucocorticoids (if applicable), (4) communication with the hospital, (5) practical issues and logistics, (6) health and lifestyle and (7) self-advocacy. The questions were answered on a 3-point Likert scale: 'yes', 'more or less' and 'no', with 'yes' as the highest (positive) score and 'no' as the lowest score for the SMS. For the questions regarding medication use, the option 'not applicable' could also be chosen if a question did not apply to the participant. The first question: 'I visit the physician because of...' was a multiple-choice question with 13 answer options, including the names of various rEC like Turner syndrome, Klinefelter syndrome, growth hormone deficiency and the options 'I do not know' and 'other'. When choosing the option 'other', patients could specify which condition

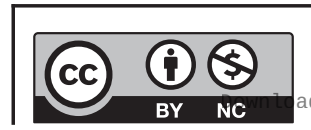

This work is licensed under a Creative Commons Attribution-NonCommercial 4.0 International License. ded from Bioscientifica.com at 04/26/2023 01:22:47PM 
they had. When the patient did not give any answer to this question, we assumed that patient did not know the name of his/her condition. The self-reported diagnosis was compared to the diagnosis retrieved from medical records.

\section{Statistical analyses}

Data were analysed using IBM SPSS Statistics version 24. Participant characteristics (retrieved from medical records) and responses to the questionnaires were summarised with percentages. Associations between all questionnaire items and gender (as assigned at birth) and between all questionnaire items and age were explored using a Mann-Whitney $U$ test or a Spearman's rho, respectively.

\section{Results}

Sixty-four patients visited the YAC, of which 58 patients filled out the questionnaire. One participant was excluded from the analysis because a parent had filled out the questionnaire. The $57(32 \mathrm{M} / 25 \mathrm{~F})$ included patients had 25 different rEC of which pituitary hormone deficiencies $(n=7)$, Klinefelter syndrome $(n=6), 46, \mathrm{XY}$ DSD $(n=6)$ and congenital adrenal hyperplasia $(n=5)$ were the most common (see Table 1 for details). Median age of participants was 17 years (IQR 17.0-18.0, range 15-26 years), 29 patients were younger than 18 years (51\%). Age did not differ significantly between males and females: median age of males was 17.0 years (IQR 17.0-18.0, range 15-26 years) and of females 18.0 years (IQR 17.0-18.5, range 17-20 years). Answers to the questionnaires are shown in Tables 2, 3, 4, 5, 6, 7, and 8.

Table 1 Diagnosis of the participants according to endocrine gland involvement.

\begin{tabular}{l} 
Diagnosis \\
\hline Adrenal \\
Classic congenital adrenal hyperplasia \\
Addison's disease \\
Isolated central adrenal insufficiency \\
Cushing's syndrome \\
Thyroid \\
Congenital central hypothyroidism \\
Hashimoto's encephalopathy \\
Multinodular goiter \\
Gonads \\
Klinefelter syndrome \\
46 XY DSD \\
Primary male hypogonadism (not Klinefelter syndrome) \\
Sex chromosome mosaicism (45X/46XY) \\
Premature Ovarian Failure \\
Hypogonadotropic hypogonadism (including \\
Kallmann syndrome) \\
Anterior pituitary \\
Combined pituitary hormone deficiency \\
Isolated growth hormone deficiency \\
Prolactinoma \\
Posterior pituitary \\
Diabetes insipidus \\
Other \\
CHARGE syndrome \\
MEN1 syndrome \\
Temple Syndrome \\
Familial pseudohypo-parathyroidism \\
Miller syndrome \\
Osteogenesis imperfecta \\
Pontine glioma \\
Silver-Russell syndrome \\
\end{tabular}

Prevalence/incidence
$1: 15,000$ (incidence) (37)
$1: 160,000-230,000$ (incidence) (38)
$1: 200,000^{a}$
$1: 400,000-1,500,000$ (incidence) (39)
$1: 20,000$ (incidence) (40)
$1: 48,000$ (prevalence) (41)
$1: 67-1000$ (incidence in non-endemic regions) (34)
$1: 670$ (incidence males) (42)
$1: 16,000$ (incidence females) (43)
Prevalence depends on type (acquired vs non-acquired) and
underlying aetiology (37)
$1: 1300$ (prevalence) (44)
$1: 10,000$ of women $<30$ years old (45)
$1: 10,000$ (incidence) (46)

1:8000 (prevalence) (47) 7

$1: 4000-10,000$ (incidence) (48) 1

$1: 10,000$ (prevalence) (49)

$1: 25,000$ (prevalence) (50)

1:8300-100,000 (incidence) (51) 1

$1: 40,000$ (incidence) (52) 2

$<1: 1,000,000^{\mathrm{a}}$

1:90,000-300,000 (prevalence) (53) 1

$<1: 1,000,000^{a}$

$1: 10,000$ (incidence) (54)

1:400,000 (incidence in 0-20 year olds) (55)

1:30,000-100,000 (prevalence) (56)

aRetrieved from www.orpha.net (portal for rare diseases and orphan drugs); ${ }^{b}$ retrieved from medical records.

https://ec.bioscientifica.com

https://doi.org/10.1530/EC-20-0304 (c) 2021 The authors Published by Bioscientifica Ltd

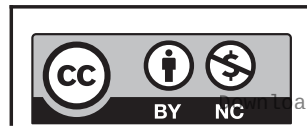

This work is licensed under a Creative Commons Attribution-NonCommercial 4.0 International License. ded from Bioscientifica.com at 04/26/2023 01:22:47PM 


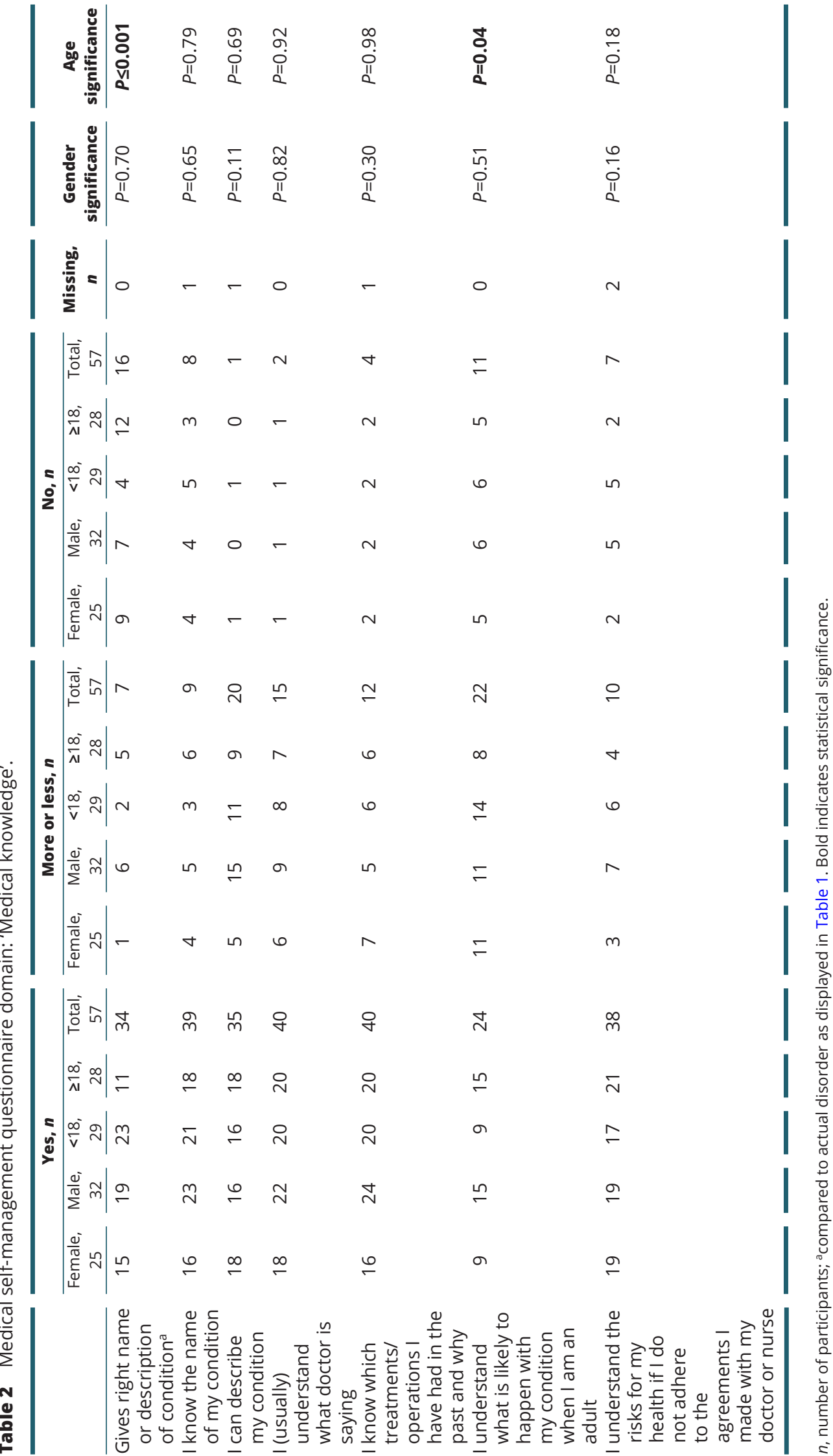




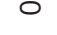




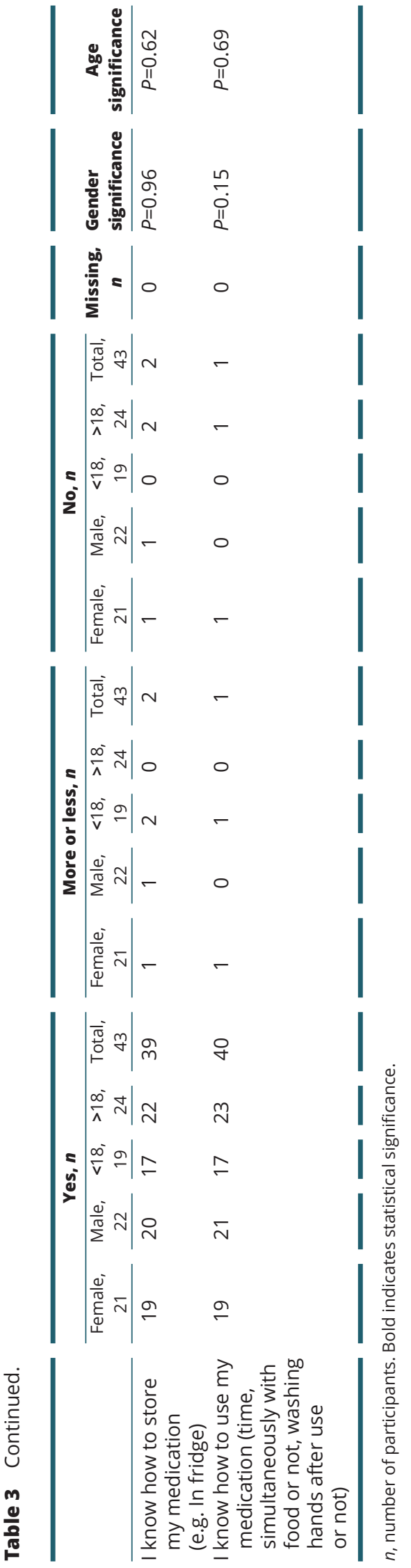

\section{Results per domain}

\section{Medical knowledge}

One out of seven patients did not know the name of their disorder. One-sixth stated they knew the name 'more or less'. Two-thirds of the participants were confident that they knew exactly what diagnosis they had. Three out of five patients indeed gave the correct name or description (Table 2).

\section{Medication}

All AYA knew what kind of medication they were using and 34/57 knew what they were using it for. Almost half of the patients ordered their own repeat prescriptions, but one-fifth fully relied on their parents or caregivers for this. About one-fifth of the patients were aware of the potential side effects of the medication they were taking (Table 3).

\section{Glucocorticoid use}

Of the glucocorticoid (GC) users ( $n=17)$, one fifth did not know that GC dose should be adjusted in case of stress, illness or surgery. They were unaware of what could happen if the GC dosage was not increased in this situation. Half of the patients did not wear an SOS item like bracelet or medallion. One-third did not always carry an emergency vial of GC with them (Table 4).

\section{Communication with the hospital}

Two-thirds of patients never talked to the doctor without the presence of parents or caregivers. 25/56 of the patients did not know what changes they could expect after transfer to adult healthcare (Table 5).

\section{Practical issues}

$41 / 57$ patients did not know the consequences of their condition for their health insurance (Table 6).

\section{Health and lifestyle}

Nine out of ten patients knew the effects of smoking, drugs and alcohol on their condition. Two-thirds understood the implications of their condition and medication on sexuality and possible pregnancy. Two-thirds had informed friends about their disorder (Table 7).

\section{Self-advocacy}

Two-thirds of the AYA knew their rights and duties concerning medical treatment. However, almost 


$$
\text { 哭 }
$$

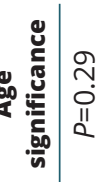<smiles>C=COCC</smiles>

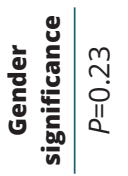

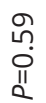

I
$\substack{0 \\ 0}$
0

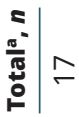

$\stackrel{\circ}{\circ}$

$\stackrel{\circ}{\circ}$

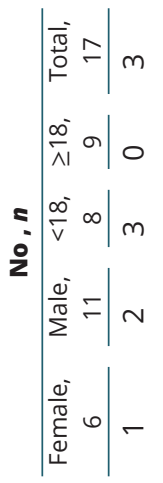

$\begin{array}{ll}\text { m } & \text { in } \\ \text { III } & \text { il } \\ 0 & 0\end{array}$

テ.
II
2

กิ
II
II
0

$\infty$
0
$i 1$
0

$\because \stackrel{\circ}{\circ}$

$\stackrel{\circ}{\circ}$

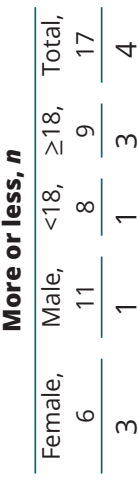

m

N

m 6

$\circ-$

$m$ in

\%

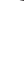

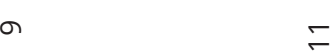

$\mp$

$-\sim$

m

$\sim$

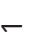

เก

$\wedge$

$\checkmark$

$\infty \quad$ เ

$\sim-$

$\wedge m$

$\infty$

m 


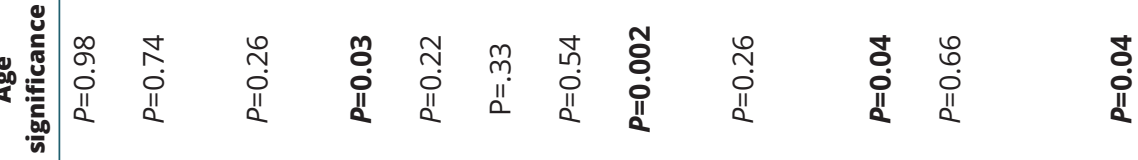

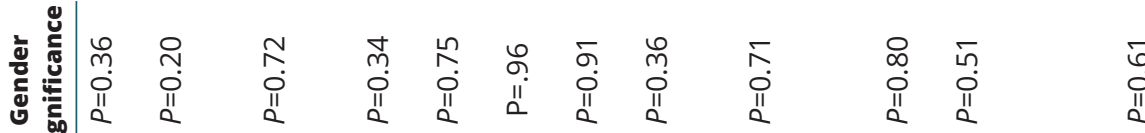

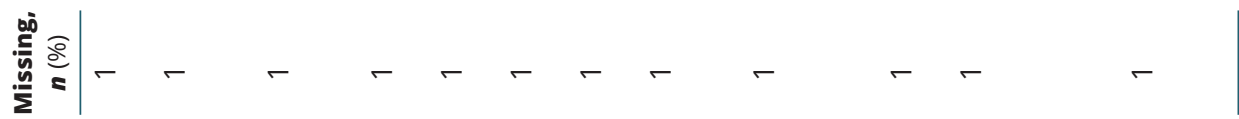

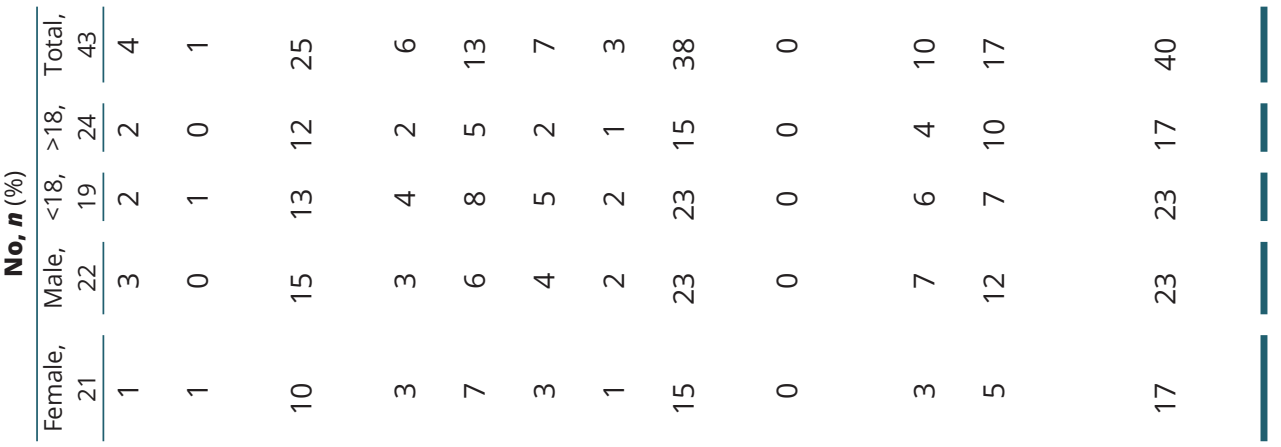

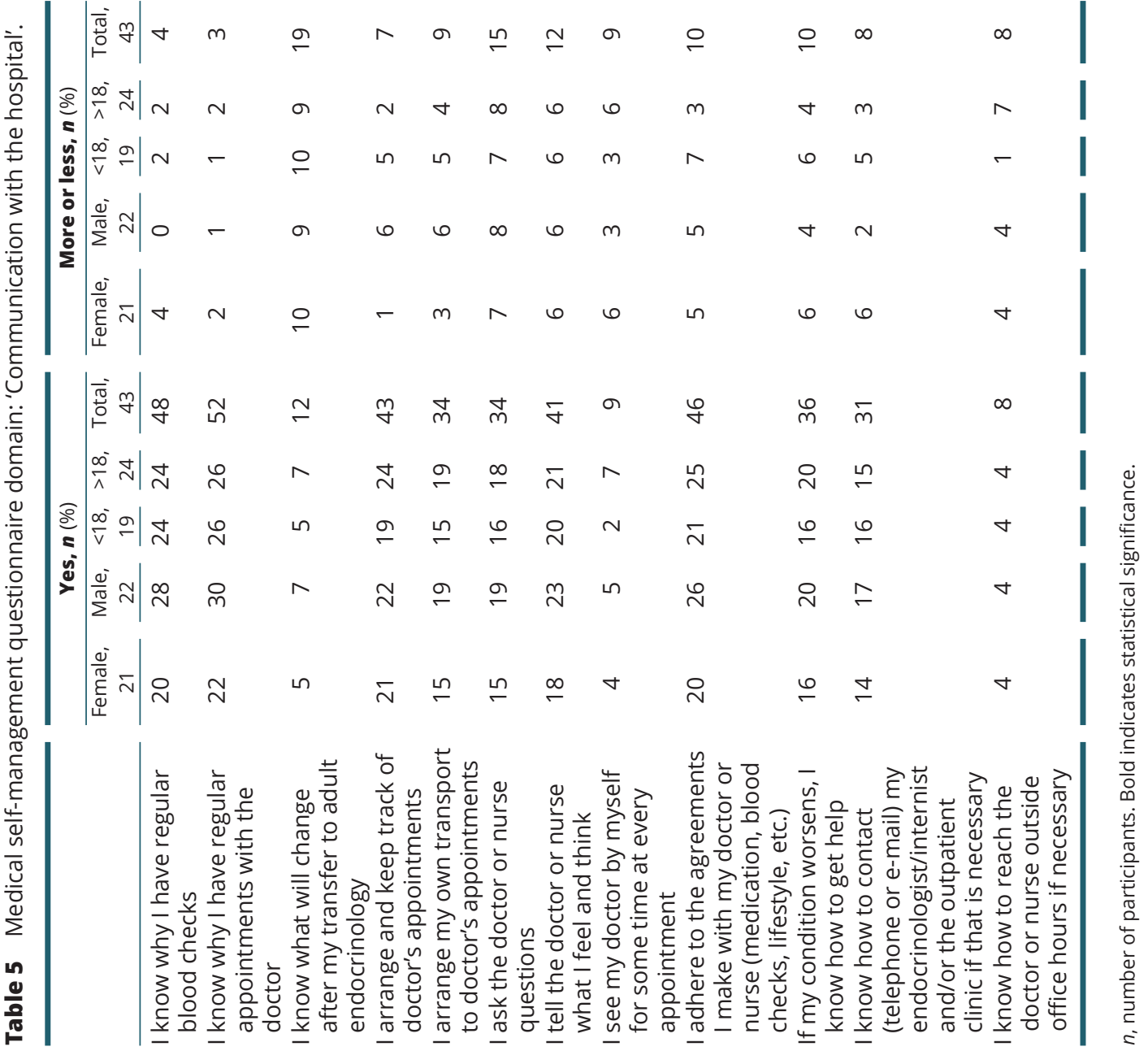



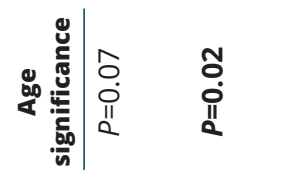

\begin{tabular}{c}
\multirow{2}{*}{} \\
0 \\
11
\end{tabular}

$\infty$
0
II
0

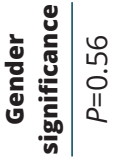

$\stackrel{0}{0}$

ֻั

ยั

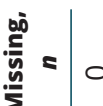

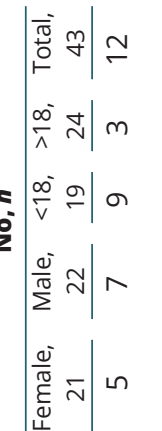

$\bar{\gamma}$

$\triangleleft$

$\stackrel{\circ}{\circ}$

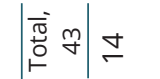

iั

$\mid \frac{\infty}{\wedge} \stackrel{\sim}{\sim}$

$\left|\frac{\infty}{v} \stackrel{\circ}{\leftarrow}\right| \wedge$

단.

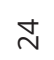

$\pi$

$\bar{N}$

잉

$\frac{\frac{\Phi}{\sigma}}{\varepsilon} \overline{\frac{\omega}{\sigma}} \mid \infty$

$\checkmark \quad$

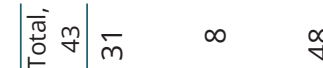

$\vdash \mid m$

$\frac{\infty}{\Lambda}^{-} \dot{\sim} \mid$

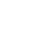

$\stackrel{\infty}{n}$

ปे

$\frac{\Phi}{\pi} \approx a$

$\sum^{\pi} N \mid$

$\frac{\frac{\Phi}{\pi}}{\bar{\nu}} \bar{\sim}$

$\simeq$

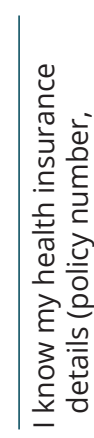

$\underline{1}$

$\checkmark$

6

$a$

$-$

으

เก

เ

เก

เก

$\stackrel{m}{m}$

몬

$\therefore$

ก

- $=\frac{\infty}{v} \stackrel{g}{v}$

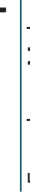

https://ec.bioscientifica.com

https://doi.org/10.1530/EC-20-0304

(c) 2021 The authors Published by Bioscientifica Ltd three-quarters of the patients did not know whether patient support organisations existed for patients with their condition (Table 8).

\section{Relation with gender}

Females were better informed about certain items regarding medication: what to do when having forgotten medication $(P=0.01)$ (Table 3$)$ and what to do with medication when travelling $(P=0.045)$ (Table 6).

\section{Relation with age}

Younger patients scored significantly higher on giving the right name or description of their condition $(P<0.001$; Table 2). Older patients more often knew what their medication was for $(P<0.005$; Table 3$)$. Older patients more often talked to the doctor without their parents present $(P<0.002$; Table 5). Compared with younger patients, older patients did not score higher on knowing how to change GC dosages in case of emergency $(P=0.29$; Table 4) or how to contact their endocrinologist if necessary $(P=0.66$; Table 5$)$. There were some borderline significant age differences $(0.01<P<0.05)$ for other items (Tables 2, 3, 4, 5, 6, 7 and 8).

\section{Discussion}

We studied transition readiness among 57 adults and young adults with rare endocrine disorders, using a webbased self-management questionnaire. In general, patients scored well on all self-management items which means that, for the majority of the patients, on the majority of the self-management items, answers were positive. SMS were only weakly related to non-modifiable factors, such as age and gender, which is in accordance with previous research $(21,23)$. As SMS correlate poorly with these nonmodifiable factors, we looked at possible ways to improve modifiable factors, like filling gaps in medical information or providing instructions about practical issues (e.g. changing GC dosages in case of emergency or contacting the endocrinologist if necessary).

\section{Medical information}

One out of seven patients did not know the name of their disorder. Likewise, one out of seven patients only knew the name of their disorder 'more or less'. Although some disorders with difficult names like 5-alpha reductase deficiency could be harder to remember than disorders like 


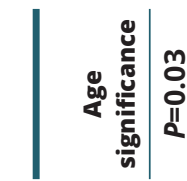
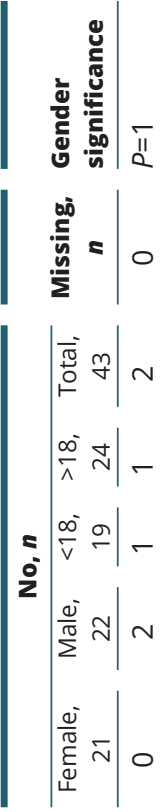

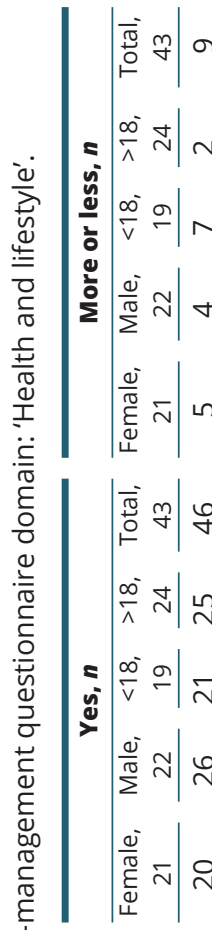

$\begin{array}{llll}\infty & \infty & 0 & m \\ 0 & 0 & 0 & 0 \\ 0 & 0 & 0 & 0 \\ 0 & 0 & 0 & \Pi 1 \\ 0 & 0 & 0\end{array}$

웅.

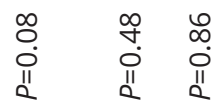

$\circ$

$\checkmark$

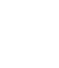

m

m

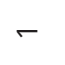

$ㅇ$

m

$\wedge$

$\infty$

N

ๆ

$\stackrel{4}{4}$

$\underset{ }{2}$

$\stackrel{9}{\circ}$

$\bar{\sim}$

ฟ

$\because \stackrel{\sim}{\sim}$

$a \simeq \infty$

$\wedge \quad \frac{\sim}{}$

$=\simeq$

n $\simeq a$

$\stackrel{m}{r}$

$\mp \quad-\quad \circ$

$\infty \quad \sim m$

$\stackrel{\sim}{\sim} \infty$

$\wedge \quad-$ n

$\approx \stackrel{\mathrm{m}}{N}$

$\infty \stackrel{n}{\sim}$

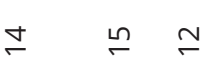

の $\stackrel{\infty}{\leftarrow}$
茎

욤

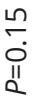

$\circ$

N

\[ \]
$\infty$
0
0
0

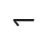

$\sim$

$\circ$

$ㅇ$

$\checkmark$

N

$N$

$m$

$+$

$\sim$

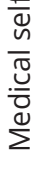

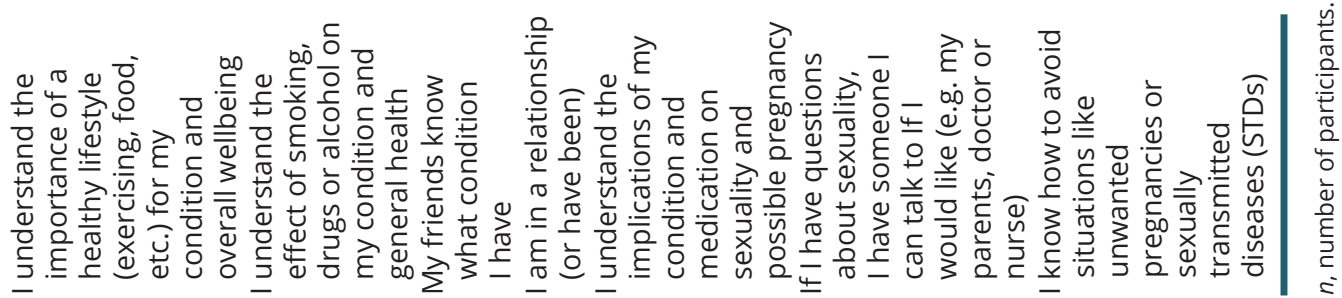


Klinefelter syndrome, this might suggest that almost one-third of the patients are not sufficiently informed about their condition at the moment of transfer to adult healthcare. This is confirmed by the answers to the question 'I can describe my condition' which was answered affirmatively by only $61 \%$. This suboptimal knowledge of the medical condition contrasts with what was found in patients with thalassemia and diabetes mellitus, where the majority could name their condition and medication (3). According to patients, medical knowledge is an important factor in transition readiness (11). This was confirmed in a systematic review by Stinson et al. (21), which showed that medical knowledge is positively related to transition readiness. Medical knowledge is therefore an important target for improving transition readiness and should also be optimised in patients with rEC. Apart from improving medical knowledge by optimising the timing, amount and 'modality' (spoken, written or video) of medical information, an informative website or smartphone app might also be useful.

\section{Practical issues}

Self-management regarding the use of medication in day-to-day life was generally well developed among the adolescents. Yet, situations that deviate from a regular day (e.g. changing GC dosages in case of emergency or contacting their endocrinologist if necessary) were generally considered challenging and this was independent of age. This is in line with a recent study by Lau et al. (3) and suggests that AYA might find it difficult to adapt to non-standard medical circumstances. In our hospital, all patients who use GC receive a hydrocortisone stress scheme along with the contact details of their doctor. Moreover, important information regarding GC use is often repeated to increase adherence. Surprisingly, we found that many patients still do not know when to adjust their dosage (and why) and that almost two-fifths do not carry an emergency vial of GC. Half of the patients do not wear an S.O.S bracelet, medallion or tattoo, even though this is strongly recommended $(8,24)$. Not all information given to patients, provided by their physician, is remembered (25). Even patients that suffer from a chronic disease, can only partly recall information (26). Apart from giving oral instructions and written information, other approaches could help to remember information. Examples include visual aids and playful learning tools (gamification) which could help to optimise medical knowledge and adherence to medical advice $(25,27)$. Furthermore, involving parents could also be beneficial to patients undergoing transition.
In a review conducted by Tully et al. $(28,29)$, coaching parents from children with type I diabetes seemed to be an easy intervention in providing psychosocial support. Although a younger age group was studied, coaching parents of (young) adults with rEC might also be helpful.

Patients were generally unaware of the possible implications of their disorder for health insurances, job searching, sexuality and possible pregnancies. In addition, our data show that the minority knew what changes they could expect after transfer to adult healthcare, which was in line with previous findings in a tertiary paediatric department (3). However, this is not a major concern as this subject is thoroughly discussed at a later stage during the visits at the YAC. Once the patient visits the YAC, the treating physician explains the differences between the paediatric and adult healthcare, along with what the patient can expect from the new adult endocrinologist and what is expected from the patient (e.g. in terms of taking responsibility and making their own decisions). Furthermore, our data demonstrate that knowledge about sexuality, pregnancy and healthcare insurances is better in older subjects, which is reassuring as it suggests that these topics will be learnt over time.

\section{Communication and other}

SMS AYA were reasonably independent in terms of planning appointments and visiting the doctor. However, they could be more independent regarding communication with the doctor. Two-thirds of the patients had never had a conversation with the doctor by themselves. This should be further improved during the transition period. If the training of communication with the doctor is not encouraged, patients might lag behind in terms of assertiveness and taking responsibility in managing their own health issues. Therefore, we recommend the use of transition checklists to detect these 'shortcomings'. Examples of well-validated checklists are TRAQ (Transition Readiness Assessment Questionnaire) (30) and TRAM (Transition Readiness and Appropriateness Measure) (31). It is important to detect these 'shortcomings' in time, so that patients have enough time to train all skills prior to transfer.

The gaps in SMS detected by transition checklists can subsequently be trained with the help of parents and caregivers, provided that both patient and parents are motivated to do so. Suris et al. (32) and Roth et al. (23) found that patients are not always motivated to learn how to be more independent. If patients are less motivated, a transition app can help to make the transition easier,

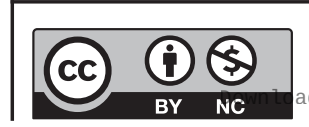




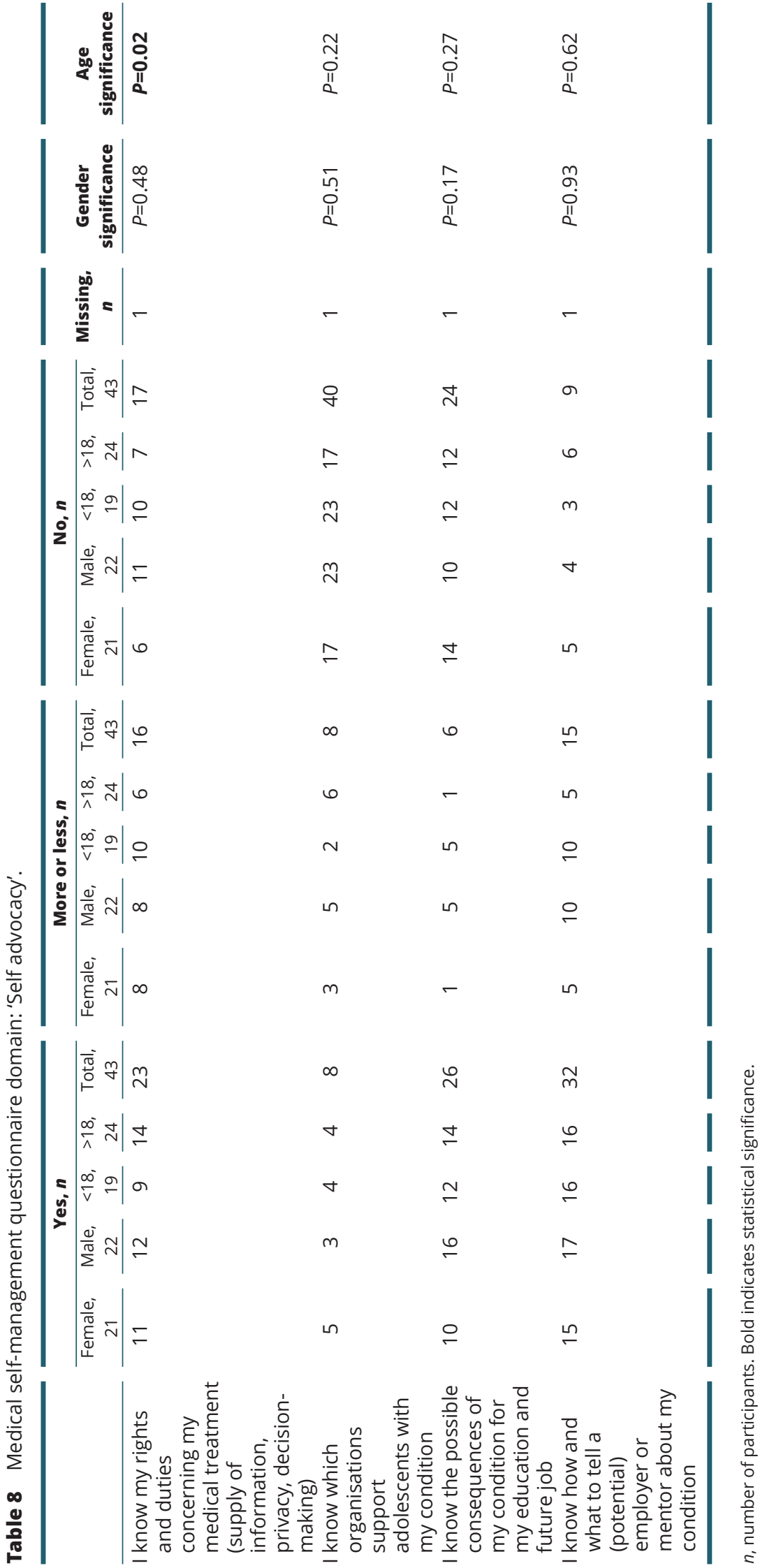


and serious gaming $(33,34,35)$ can be a way to make self-management fun. This way, e-technology can help the patient to become more independent.

Like every study, our study has strengths and limitations. The major strength is the unique population of patients with rare disorders. Limitations of our study include confined generalisability and small sample size. Our participants may not be representative for all AYA with $\mathrm{rEC}$, as enrolment took place in one medical centre. Furthermore, social desirability could have influenced the answers, leading to an overestimation of SMS (36). Moreover, as the patients filled out the questionnaires at home, we cannot be certain that they did not receive help from parents or caregivers. Nonetheless, this is the first study, to our knowledge, that has assessed an extensive variety of self-management items among AYA with rEC.

In conclusion, we assessed transition readiness among 57 adolescents and young adults with rare endocrine disorders. In general, patients scored well on all self-management items. However, there is room for improvement of SMS, with regard to knowledge of the disorder, practical issues (like dealing with unexpected situations, collecting repeat medication, healthcare insurance) and communication with the hospital. SMS were only weakly related to non-modifiable factors like age or gender. Therefore we recommend focusing on other factors to improve transition readiness. First, the timing, amount and 'mode of administration' (i.e. spoken, written, e-technology) of medical information should be individualised and repeated. Secondly, transition checklist should be used to actively search for gaps in SMS. Thirdly, detected 'shortcomings' in communication and other SMS can be trained with the help of parents, caregivers or e-technology (apps and/or serious games). These measures require relatively little effort and can help AYA bridge the gap between paediatric and adult endocrinology.

\section{Supplementary materials}

This is linked to the online version of the paper at https://doi.org/10.1530/ EC-20-0304

\section{Declaration of interest}

The authors declare that there is no conflict of interest that could be perceived as prejudicing the impartiality of the research reported.

\section{Funding}

This research did not receive any specific grant from any funding agency in the public, commercial or not-for-profit sector.

\section{Acknowledgements}

The authors made use of '"Ready Steady Go" and "Hello to adult services" developed by the Transition Steering Group led by Dr Arvind Nagra, paediatric nephrologist and clinical lead for transitional care at Southampton Children's Hospital, University Hospital Southampton NHS Foundation Trust. This was based on the work of (1) S Whitehouse and MC Paone. Bridging the gap from youth to adulthood. Contemporary Pediatrics; 1998, December 13-16. (2) Paone MC, Wigle M, Saewyc E. The ON TRAC model for transitional care of adolescents. Prog Transplant 2006;16:291-302. (3) Janet E McDonagh et al., J Child Health Care 2006;10(1):22-42'. Further information can be found at www.uhs.nhs.uk/ readysteadygo.

\section{References}

1 Gleeson H, Davis J, Jones J, O'Shea E \& Clayton PE. The challenge of delivering endocrine care and successful transition to adult services in adolescents with congenital adrenal hyperplasia: experience in a single centre over 18 years. Clinical Endocrinology 201378 23-28. (https://doi.org/10.1111/cen.12053)

2 Wisk LE, Finkelstein JA, Sawicki GS, Lakoma M, Toomey SL, Schuster MA \& Galbraith AA. Predictors of timing of transfer from pediatric- to adult-focused primary care. JAMA Pediatrics 2015169 e150951. (https://doi.org/10.1001/jamapediatrics.2015.0951)

3 Lau SC, Azim E, Abdul Latiff Z, Syed Zakaria SZ, Wong SW, Wu LL, Hong SS, Alias H, Loh CK, Abdul Aziz B, et al. Transition care readiness among patients in a tertiary paediatric department. Medical Journal of Malaysia 201873 382-387.

4 Godbout A, Tejedor I, Malivoir S, Polak M \& Touraine P. Transition from pediatric to adult healthcare: assessment of specific needs of patients with chronic endocrine conditions. Hormone Research in Paediatrics 201278 247-255. (https://doi.org/10.1159/000343818)

5 Gumidyala AP, Greenley RN, Plevinsky JM, Poulopoulos N, Cabrera J, Lerner D, Noe JD, Walkiewicz D, Werlin S \& Kahn SA. Moving on: transition readiness in adolescents and young adults with IBD. Inflammatory Bowel Diseases 201824 482-489. (https://doi. org/10.1093/ibd/izx051)

6 Cole R, Ashok D, Razack A, Azaz A \& Sebastian S. Evaluation of outcomes in adolescent inflammatory bowel disease patients following transfer from pediatric to adult health care services: case for transition. Journal of Adolescent Health 201557 212-217. (https:// doi.org/10.1016/j.jadohealth.2015.04.012)

7 American Academy of Pediatrics, American Academy of Family Physicians, American College of Physicians, Transitions Clinical Report Authoring Group, Cooley WC \& Sagerman PJ. Supporting the health care transition from adolescence to adulthood in the medical home. Pediatrics 2011128 182-200. (https://doi.org/10.1542/ peds.2011-0969)

8 Haarbauer-Krupa J, Alexander NM, Mee L, Johnson A, Wise J, Arora Gupta N, Schechter MS, Wasilewski-Masker K \& Gilleland Marchak J. Readiness for transition and health-care satisfaction in adolescents with complex medical conditions. Child: Care, Health and Development 201945 463-471. (https://doi.org/10.1111/cch.12656)

9 Barlow J, Wright C, Sheasby J, Turner A \& Hainsworth J. Selfmanagement approaches for people with chronic conditions: a review. Patient Education and Counseling 200248 177-187. (https:// doi.org/10.1016/s0738-3991(02)00032-0)

10 Lorig KR \& Holman H. Self-management education: history, definition, outcomes, and mechanisms. Annals of Behavioral Medicine 200326 1-7. (https://doi.org/10.1207/S15324796ABM2601_01)

11 Kulandaivelu Y, Lalloo C, Ward R, Zempsky WT, Kirby-Allen M, Breakey VR, Odame I, Cambell F, Amaria K, Simpson EA, et al. Exploring the needs of adolescents with sickle cell disease to inform a digital self-management and transitional care program: qualitative

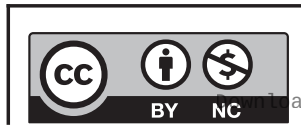

This work is licensed under a Creative Commons Attribution-NonCommercial 4.0 International License. ded from Bioscientifica.com at 04/26/2023 01:22:47PM 
study. JMIR Pediatrics and Parenting 20181 e11058. (https://doi org/10.2196/11058)

12 Loew M, Williams JL, Russell K, Rupff R, Hankins JS \& Porter J. The adolescent and caregiver sickle cell disease self-management skills checklist: preliminary reliability and validity. Journal of Pediatric Hematology/Oncology 202042 12-19. (https://doi.org/10.1097/ MPH.0000000000001618)

13 Saxby N, Beggs S, Battersby M \& Lawn S. What are the components of effective chronic condition self-management education interventions for children with asthma, cystic fibrosis, and diabetes? A systematic review. Patient Education and Counseling 2019102 607-622. (https://doi.org/10.1016/j.pec.2018.11.001)

14 Shapiro JM, El-Serag HB, Gandle C, Peacock C, Denson LA, Fishman LN, Hernaez R \& Hou JK. Recommendations for successful transition of adolescents with inflammatory bowel diseases to adult care. Clinical Gastroenterology and Hepatology 202018 276.e2-289.e2. (https://doi.org/10.1016/j.cgh.2019.04.063)

15 McCarthy MM \& Grey M. Type 1 diabetes self-management from emerging adulthood through older adulthood. Diabetes Care 201841 1608-1614. (https://doi.org/10.2337/dc17-2597)

16 Vloemans AF, Eilander MMA, Rotteveel J, Bakker-van Waarde WM, Houdijk ECAM, Nuboer R, Winterdijk P, Snoek FJ \& De-Wit M. Youth with type 1 diabetes taking responsibility for selfmanagement: the importance of executive functioning in achieving glycemic control: results from the longitudinal DINO study. Diabetes Care 201942 225-231. (https://doi.org/10.2337/dc181143)

17 Palermo TM, Zempsky WT, Dampier CD, Lalloo C, Hundert AS, Murphy LK, Bakshi N \& Stinson JN. iCanCope with sickle cell pain: design of a randomized controlled trial of a smartphone and web-based pain self-management program for youth with sickle cell disease. Contemporary Clinical Trials 201874 88-96. (https://doi. org/10.1016/j.cct.2018.10.006)

18 Melita N, Diaz-Linhart Y, Kavanagh PL \& Sobota A. Developing a problem-solving intervention to improve self-management and transition readiness in adolescents with sickle cell disease. Journal of Pediatric Nursing 201946 26-32. (https://doi.org/10.1016/j. pedn.2019.02.006)

19 Joslin B, Langman C, Nishi L \& Ghossein C. Assessing success in transitioning of young adults from pediatric to adult kidney practice. BMC Nephrology 202021 8. (https://doi.org/10.1186/s12882-0191665-7)

20 Schwartz LA, Tuchman LK, Hobbie WL \& Ginsberg JP. A socialecological model of readiness for transition to adult-oriented care for adolescents and young adults with chronic health conditions. Child: Care, Health and Development 201137 883-895. (https://doi. org/10.1111/j.1365-2214.2011.01282.x)

21 Stinson J, Kohut SA, Spiegel L, White M, Gill N, Colbourne G, Sigurdson S, Duffy KW, Tucker L, Stringer E, et al. A systematic review of transition readiness and transfer satisfaction measures for adolescents with chronic illness. International Journal of Adolescent Medicine and Health 201426 159-174. (https://doi.org/10.1515/ ijamh-2013-0512)

22 Monaghan M \& Baumann K. Type 1 diabetes: addressing the transition from pediatric to adult-oriented health care. Research and Reports in Endocrine Disorders 20166 31-40. (https://doi.org/10.2147/ RRED.S56609)

23 Roth JD, Szymanski KM, Cain MP \& Misseri R. Factors impacting transition readiness in young adults with neuropathic bladder. Journal of Pediatric Urology 202016 45.e1-45.e7. (https://doi. org/10.1016/j.jpurol.2019.10.017)

24 Shulman DI, Palmert MR, Kemp SF \& Lawson Wilkins Drug and Therapeutics Committee. Adrenal insufficiency: still a cause of morbidity and death in childhood. Pediatrics 2007119 e484-e494. (https://doi.org/10.1542/peds.2006-1612)
25 Kessels RP. Patients' memory for medical information. Journal of the Royal Society of Medicine 200396 219-222. (https://doi.org/10.1258/ jrsm.96.5.219)

26 Richard C, Glaser E \& Lussier MT. Communication and patient participation influencing patient recall of treatment discussions. Health Expectations 201720 760-770. (https://doi.org/10.1111/ hex.12515)

27 Drummond D, Monnier D, Tesniere A \& Hadchouel A. A systematic review of serious games in asthma education. Pediatric Allergy and Immunology 201728 257-265. (https://doi.org/10.1111/pai.12690)

28 Tully C, Shneider C, Monaghan M, Hilliard ME \& Streisand R. Peer coaching interventions for parents of children with Type 1 diabetes. Current Diabetes Reports 201717 39. (https://doi.org/10.1007/s11892017-0870-7)

29 Tully V, Murphy D, Fioratou E, Chaudhuri A, Shaw J \& Davey P. Learning from errors: assessing final year medical students' reflection on safety improvement, five year cohort study. BMC Medical Education 201818 57. (https://doi.org/10.1186/s12909-0181173-7)

30 Wood DL, Sawicki GS, Miller MD, Smotherman C, Lukens-Bull K, Livingood WC, Ferris M \& Kraemer DF. The transition readiness assessment questionnaire (TRAQ): its factor structure, reliability, and validity. Academic Pediatrics 201414 415-422. (https://doi. org/10.1016/j.acap.2014.03.008)

31 Santosh P, Singh J, Adams L, Mastroianni M, Heaney N, Lievesley K, Sagar-Ouriaghli I, Allibrio G, Appleton R, Davidocić N, et al. Validation of the transition readiness and appropriateness measure (TRAM) for the Managing the Link and Strengthening Transition from Child to Adult Mental Healthcare in Europe (MILESTONE) study. BMJ Open 202010 e033324. (https://doi.org/10.1136/ bmjopen-2019-033324)

32 Suris JC, Akre C \& Rutishauser C. How adult specialists deal with the principles of a successful transition. Journal of Adolescent Health 200945 551-555. (https://doi.org/10.1016/j. jadohealth.2009.05.011)

33 Brown SJ, Lieberman DA, Germeny BA, Fan YC, Wilson DM \& Pasta DJ. Educational video game for juvenile diabetes: results of a controlled trial. Medical Informatics 199722 77-89. (https://doi. org/10.3109/14639239709089835)

34 Kumar VS, Wentzell KJ, Mikkelsen T, Pentland A, Laffel LM \& The D. The DAILY (daily automated intensive log for youth) trial: a wireless, portable system to improve adherence and glycemic control in youth with diabetes. Diabetes Technology and Therapeutics 20046 445-453. (https://doi.org/10.1089/1520915041705893)

35 Rubin DH, Leventhal JM, Sadock RT, Letovsky E, Schottland P, Clemente I \& McCarthy P. Educational intervention by computer in childhood asthma: a randomized clinical trial testing the use of a new teaching intervention in childhood asthma. Pediatrics 198677 $1-10$.

36 Krumpal I. Determinants of social desirability bias in sensitive surveys: a literature review. Quality and Quantity 201347 2025-2047. (https://doi.org/10.1007/s11135-011-9640-9)

37 Merke D \& Kabbani M. Congenital adrenal hyperplasia: epidemiology, management and practical drug treatment. Paediatric Drugs 20013 599-611. (https://doi.org/10.2165/00128072200103080-00005)

38 Betterle C, Presotto F \& Furmaniak J. Epidemiology, pathogenesis, and diagnosis of Addison's disease in adults. Journal of Endocrinological Investigation 201942 1407-1433. (https://doi. org/10.1007/s40618-019-01079-6)

39 Sharma ST, Nieman LK \& Feelders RA. Cushing's syndrome: epidemiology and developments in disease management. Clinical Epidemiology 20157 281-293. (https://doi.org/10.2147/CLEP.S44336) 40 McGrath N, Hawkes CP, McDonnell CM, Cody D, O'Connell SM, Mayne PD \& Murphy NP. Incidence of congenital hypothyroidism https://ec.bioscientifica.com https://doi.org/10.1530/EC-20-0304 (c) 2021 The authors Published by Bioscientifica Ltd

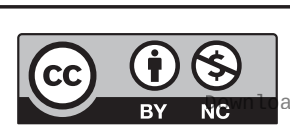

This work is licensed under a Creative Commons Attribution-NonCommercial 4.0 International License. ded from Bioscientifica.com at $04 / 26 / 2023$ 01:22:47PM 
over 37 years in Ireland. Pediatrics 2018142 e20181199. (https://doi. org/10.1542/peds.2018-1199)

41 Mocellin R, Walterfang M \& Velakoulis D. Hashimoto's encephalopathy: epidemiology, pathogenesis and management. CNS Drugs 200721 799-811. (https://doi.org/10.2165/00023210200721100-00002)

42 Gravholt CH, Chang S, Wallentin M, Fedder J, Moore P \& Skakkebaek A. Klinefelter syndrome: integrating genetics, neuropsychology, and endocrinology. Endocrine Reviews 201839 389-423. (https://doi.org/10.1210/er.2017-00212)

43 Berglund A, Johannsen TH, Stochholm K, Viuff MH, Fedder J, Main KM \& Gravholt CH. Incidence, prevalence, diagnostic delay, and clinical presentation of female $46, \mathrm{XY}$ disorders of sex development. Journal of Clinical Endocrinology and Metabolism 2016 101 4532-4540. (https://doi.org/10.1210/jc.2016-2248)

44 Tuke MA, Ruth KS, Wood AR, Beaumont RN, Tyrrell J, Jones SE, Yaghootkar H, Turner CLS, Donohoe ME, Brooke AM, et al. Mosaic Turner syndrome shows reduced penetrance in an adult population study. Genetics in Medicine 201921 877-886. (https://doi. org/10.1038/s41436-018-0271-6)

45 Baker VL. Primary ovarian insufficiency in the adolescent. Current Opinion in Obstetrics and Gynecology 201325 375-381. (https://doi. org/10.1097/GCO.0b013e328364ed2a)

46 Fraietta R, Zylberstejn DS \& Esteves SC. Hypogonadotropic hypogonadism revisited. Clinics 201368 (Supplement 1) 81-88. (https://doi.org/10.6061/clinics/2013(sup01)09)

47 Fang Q, George AS, Brinkmeier ML, Mortensen AH, Gergics P, Cheung LY, Daly AZ, Ajmal A, Pérez Millán MI, Bilge Ozel AB, et al. Genetics of combined pituitary hormone deficiency: roadmap into the genome era. Endocrine Reviews 201637 636-675. (https://doi. org/10.1210/er.2016-1101)

48 Alatzoglou KS, Webb EA, Le Tissier P \& Dattani MT. Isolated growth hormone deficiency (GHD) in childhood and adolescence: recent advances. Endocrine Reviews 201435 376-432. (https://doi. org/10.1210/er.2013-1067)

49 Ciccarelli A, Daly AF \& Beckers A. The epidemiology of prolactinomas. Pituitary 20058 3-6. (https://doi.org/10.1007/s11102005-5079-0)

50 Hui C \& Radbel JM. Diabetes insipidus. StatPearls, 2021. (available at: https://www.ncbi.nlm.nih.gov/books/NBK470458/)

51 Blake KD \& Prasad C. CHARGE syndrome. Orphanet Journal of Rare Diseases 2006134 . (https://doi.org/10.1186/1750-1172-1-34)

52 Thakker RV, Newey PJ, Walls GV, Bilezikian J, Dralle H, Ebeling PR, Melmed S, Sakurai A, Tonelli F, Brandi ML, et al. Clinical practice guidelines for multiple endocrine neoplasia type 1 (MEN1). Journal of Clinical Endocrinology and Metabolism 201297 2990-3011. (https:// doi.org/10.1210/jc.2012-1230)

53 Mantovani G, Bastepe M, Monk D, de Sanctis L, Thiele S, Usardi A, Ahmed SF, Bufo R, Choplin T, de Filippo G, et al. Diagnosis and management of pseudohypoparathyroidism and related disorders: First International Consensus Statement. Nature Reviews: Endocrinology 201814 476-500. (https://doi.org/10.1038/s41574-0180042-0)

54 Marini JC, Forlino A, Bachinger HP, Bishop NJ, Byers PH, Paepe A, Fassier F, Fratzl-Zelman N, Kozloff KM, Krakow D, et al. Osteogenesis imperfecta. Nature Reviews: Disease Primers 20173 17052. (https:// doi.org/10.1038/nrdp.2017.52)

55 Veldhuijzen van Zanten SE, Jansen MH, Sanchez Aliaga E, van Vuurden DG, Vandertop WP \& Kaspers GJ. A twenty-year review of diagnosing and treating children with diffuse intrinsic pontine glioma in the Netherlands. Expert Review of Anticancer Therapy 2015 15 157-164. (https://doi.org/10.1586/14737140.2015.974563)

56 Abu-Amero S, Monk D, Frost J, Preece M, Stanier P \& Moore GE. The genetic aetiology of Silver-Russell syndrome. Journal of Medical Genetics 200845 193-199. (https://doi.org/10.1136/ jmg.2007.053017)

Received in final form 14 January 2021

Accepted 19 March 2021

Accepted Manuscript published online 25 March 2021
This work is licensed under a Creative Commons Attribution-NonCommercial 4.0 International License. ded from Bioscientifica.com at 04/26/2023 01:22:47PM 